DOI 10.37882/2500-3682.2021.12.05

\title{
ВИЗУАЛЬНЫЙ КОМПОНЕНТ ОРГАНИЗАЦИОННОЙ КУЛЬТУРЫ: СРАВНИТЕЛЬНЫЙ ПСИХОЛОГИЧЕСКИЙ АНАЛИЗ
}

\section{VISUAL COMPONENT \\ OF ORGANIZATIONAL CULTURE: COMPARATIVE PSYCHOLOGICAL ANALYSIS}

\section{T. Byundyugova}

Summary: The paper contains the results of a study of the organizational culture of enterprises. The article considers the idea of the visual component of organizational culture as a key factor in analyzing the possibilities of its transformation, since it is reflected in the internal consciousness of employees and management, has a pronounced affective content, which contributes to a more complete and conscious acceptance of organizational culture. The purpose of the study is to compare the types of culture in an organization by the criterion of the severity of the visual component, to study the ideas of ideal and real culture, taking into account the personal parameters of employees. Research objectives: to select methods for measuring different components of culture in an organization for comparative analysis; to measure the components of culture in organizations with different severity of the visual component within its translation (symbols, images, infographics). The main idea is related to the fact that the level of acceptance and division of organizational culture is related to the number of visual components in its design and translation, which are understandable to employees and coincide with their values, meanings and ideas. It was revealed that respondents with different levels of coincidence of ideas about the existing and preferred culture have different levels of loyalty and social trust, which affects the effectiveness of the introduction of a new organizational culture. Of great importance is the assessment of the cognitive construct «culture in my organization», which is part of the inner world of the individual, containing values, norms and rules related to behavior in the organization and in work processes.

Keywords: organizational culture, values, cognitive construct, visual components of culture, values, semantic content of culture.
$\mathrm{B}$ настоящее время в организациях наблюдается множество тенденций, которые ведут к трансформациям, реорганизации, быстрому перестроению управленческих функций, работе с персоналом, внедрению инновационных практик в работу. Все эти факторы повышают интерес к использованию в качестве ключевого фактора таких преобразований организационную культуру, поскольку она оказывает существенное воздействие на эффективность, развитие и стабильное существование организации.

Культура позволяет реализовать максимально есте-
Бюндюгова Татьяна Вячеславовна

К.nсх.н., доцент, Южный университет (ИУБиП) tach_29@mail.ru

Аннотация: Работа содержите результаты исследования организационной культуры предприятий. В статье рассмотрена идея 0 визуальном компоненте организационной культуры как ключевом факторе анализа возможностей ее трансформации, поскольку именно он отражается во внутреннем плане сознания сотрудников и руководства, имеет выраженное аффективное содержание, что способствует более полному и осознанному принятию организационной культуры. Цель исследования - сравнить типы культуры в организации по критерию выраженности визуального компонента, изучить представления 06 идеальной и реальной культуре с учетом личностных параметров сотрудников. Задачи исследования: подобрать методики для измерения разных составляющих культуры в организации для сравнительного анализа; измерить составляющие культуры в организациях с разной выраженностью визуального компонента в рамках ее трансляции (символы, образы, инфографика). Основная идея связана с тем, что уровень принятия и разделения организационной культуры связан с количеством визуальных компонентов в ее оформлении и трансляции, которые понятны сотрудникам и совпадают с их ценностями, смыслами и представлениями. Было выявлено, что респонденты с различным уровнем совпадений представлений 0 существующей и предпочитаемой культуре обладают разным уровнем лояльности и социального доверия, что оказывает влияние на эффективность внедрения новой организационной культуры. Большое значение имеет оценка когнитивного конструкта «культура в моей организации», который является частью внутреннего мира личности, содержащей ценности, нормы и правила, связанные с поведением в организации и в рабочих процессах.

Ключевые слова: организационная культура, ценности, когнитивный конструкт, визуальные компоненты культуры, ценности, смысловое содержание культуры.

ственно и эффективно стратегию развития организации, она определяет общие цели, миссию, систему ценностей, паттернов поведения сотрудников, на основе транслируемых руководителем идей и ключевых посылов, сосредоточенных в визуальном формате (как правило) [2].

В настоящее время многие организации проходят сложный период, связанный с ситуацией пандемии, высоким уровнем неопределенности, постоянно меняющихся условий работы. Поэтому все более актуальным для них становится объединение сотрудников вокруг ценностей, миссии, которые должны быть системно и 
грамотно оформлены и понятны большинству тех, кто работает в организации. В современных исследованиях отмечается низкий приоритет развития культуры в организации, оценка ее как социальной формы нематериальной мотивации в лучшем случае, при этом фокус внимания смещен на меры экономии, сокращение сотрудников, мощностей, производств, услуг. При этом развитие целенаправленное формирование и развитие культуры может быть более целесообразным способом проживания кризисных и сложных ситуаций в организации [4].

Одна из ключевых современных управленческих проблем - непонимание руководством возможностей преодоления сложных периодов за счет сильно развитой культуры. Низкий уровень развития культуры в организации может стать причиной эмоциональной напряженности между сотрудниками, ростом неконструктивных способов решения конфликтов и споров, в целом, их увеличением, повышением тревожности и профессиональных стрессов. Все это подтверждает необходимость учета существующей культуры, ее типа и уровня, а также целенаправленное развитие [6].

Общее понятие организационной культуры, основанное на разработках Х. Шварца, С. Шекшня, Б. Дэвиса, С. Филпа, Г. Латфуллина, О. Громова, Э. Шейна, может быть систематизировано следующим образом: смысловая система, которая транслируется с помощью языка, символов, знаков с целью презентации особого ощущения организационной реальности сотрудниками. Привитие культуры может быть реализовано в директивном или аффективном ключе [5].

Термин «организационная культура» не имеет единого значения как в отечественной, так и зарубежной теории и практике. Единство состоит в понимании многомерности и сложности данного конструкта, которое часто неоднородно воспринимается сотрудниками, при этом влияя на их поведение и профессиональную деятельность.

С целью повышения эффективности фокус исследования организационной культуры должен быть смещен в пространство внутренней психологической реальности: необходимо более четкое понимание алгоритмов того, как отдельные компоненты культуры воспринимаются сотрудниками, отражаются в их сознании и вписываются в их внутренний мир и впоследствии разделяются ими. Для этого требуется проанализировать то как описывают и понимают сотрудники окружающее физическое пространство организации, какой когнитивный конструкт она образует в пространстве их внутреннего плана сознания. Непротиворечивость понимания ценностей и норм, общий внутренний сленг, алгоритмы поведения в различных профессиональных и рабочих ситуациях достигаются за счет целенаправленно сформированной культуры организации. За счет этого проявляется и развивается «общая психология группы», глубинное коллективное мышление, систему оценок и чувств. Все это позволяет транслировать определенные мысли и ценности в своей работе, усиливая ее эффективность и конкурентоспособность организации [1].

Чем больше сотрудники разделяют общие положения культуры, тем эффективнее они осмысляют рабочие задачи, профессиональное окружение, собственные действия и решения в интересах организации.

Все это позволяет говорить о некотором «системном образе» культуры как когнитивном конструкте о процессах в организации и взаимоотношении сотрудников, решении стратегических задач. Организационная культура - процессуальный когнитивный конструкт, который трансформируется, создается, развивается постоянно, не оставаясь в статичном состоянии.

Ключевая характеристика восприятия когнитивного конструкта «культура организации» - целостность - как система высокого уровня единства и совпадения представлений отдельных сотрудников о ее функционировании и развитии, разделения ими идей, которые существуют в глубинных и поверхностных ее пластах. Здесь важно отметить два ключевых фактора непротиворечивости данного конструкта:

- большую часть когнитивного конструкта «организационная культура» разделяет и одинаково понимает большинство сотрудников;

- нет противоречий между представлениями об идеальной и реально существующей культуре организации [7].

Необходимость изучения когнитивного конструкта «организационная культура» как системы представлений очевидна, поскольку внешние его презентации часто несут мало определяющей информации, бессистемной и иногда противоречивой. Они позволяют проанализировать верхний уровень культуры организации. Для изучения глубинных уровней организационной культуры необходимо анализировать систему символов и смыслов, их сложнее дифференцировать и выразить количественно, но именно визуальные знаки дают о ней наиболее четкое представление [2].

Помимо этого, необходимо анализировать ценности, которые содержит культура, поскольку именно они отражают истинное системное положение дел относительно функционирования организации. Это сложно дифференцировать и описать только с помощью наблюдения, при этом можно интерпретировать описания организационной культуры сотрудниками разного уровня, а также проанализировать разницу между представлениями 
об идеальном типе организационной культуры и реально существующей ее форме.

Исследование типов организационной культуры и дифференциации между реально существующим типом и представлениями о ее идеальной форме проводилось на базе двух производственных предприятий г. Таганрога (предприятия из примерно одинаковой сферы, что позволило более точно сравнить полученные данные и результаты).

Цель исследования - сравнить типы культуры в организации по критерию выраженности визуального компонента, изучить представления об идеальной и реальной культуре с учетом личностных параметров сотрудников.

Задачи исследования:

- подобрать методики для измерения разных составляющих культуры в организации для сравнительного анализа;

- измерить составляющие культуры в организациях с разной выраженностью визуального компонента в рамках ее трансляции (символы, образы, инфографика).

Предмет исследования: сравнительный анализ эффективности визуального компонента культуры в разных организациях.

Гипотеза исследования: уровень принятия и разделения организационной культуры связан с количеством визуальных компонентов в ее оформлении и трансляции.

Исследование проводилось с участием 215 человек, из них 95 мужчин и 120 женщин в возрасте от 24 до 55 лет, участники исследования работают в одной и той же организации больше 3 лет в одной и той же организа- ции, 69\% с высшим образованием, 31\% - со средним.

В исследовании использовались следующие методики:

- анкетирование;

- беседа в свободной форме по вопросам восприятия организационной культуры и желания участия в ее развитии;

- тест определения типа организационной культуры (К.Камерон; Р. Куинн);

- шкала оценки межличностного доверия Дж. Роттера;

- шкала оценки организационной лояльности Н. Аллен - Дж. Мейера.

Также был использован корреляционный анализ и анализ различий.

Bсе респонденты принимали участие в исследовании добровольно, исследование было согласовано с руководством, организовано на базе предприятий 1 и 2 в свободное от работы время, чтобы снизить уровень отвлекаемости и стресса от участия.

\section{Результаты исследования}

По методике определения типа организационной культуры были выделены особенности культур, существующие на двух предприятиях, на предмет типа культуры и совпадения представлений об имеющейся и желаемой культуре среди сотрудников.

На предприятии 1 представление о культуре реальной и желаемой совпадают практически полностью (рисунок 1).

По данным рисунка 1 можно говорить о том, что на предприятии 1 как существующая отмечена бюрократическая культура, а как предпочитаемая - рыночная куль-

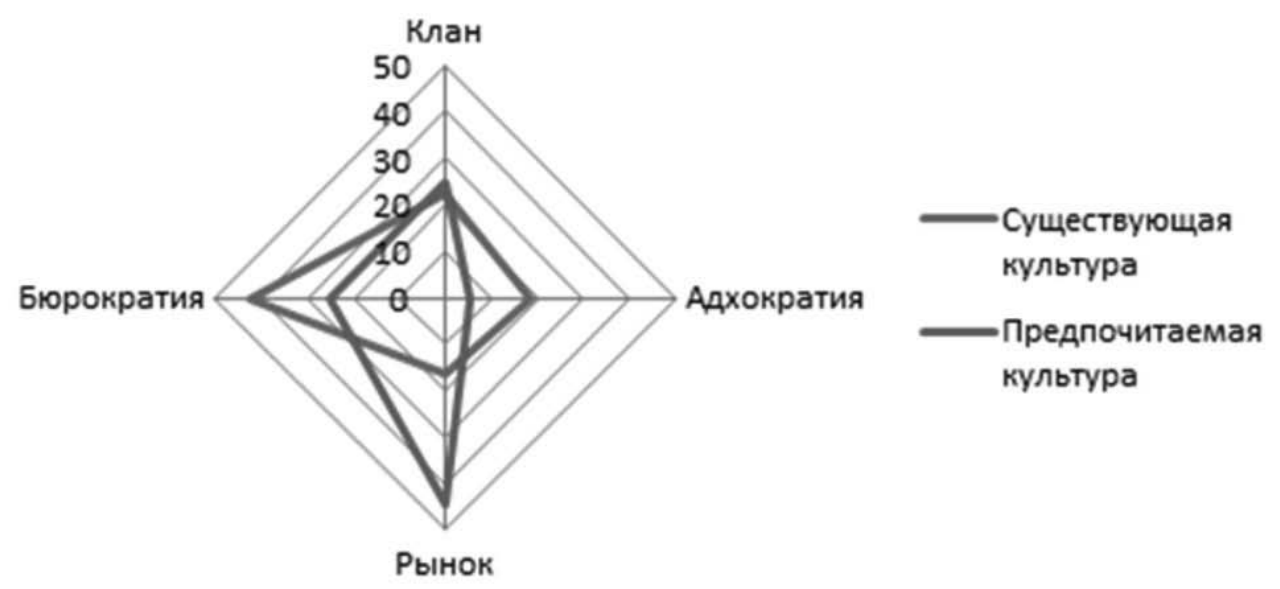

Рис. 1. Выраженность типов организационной культуры и соотношения существующей и предпочитаемой культуры сотрудников предприятия 1 


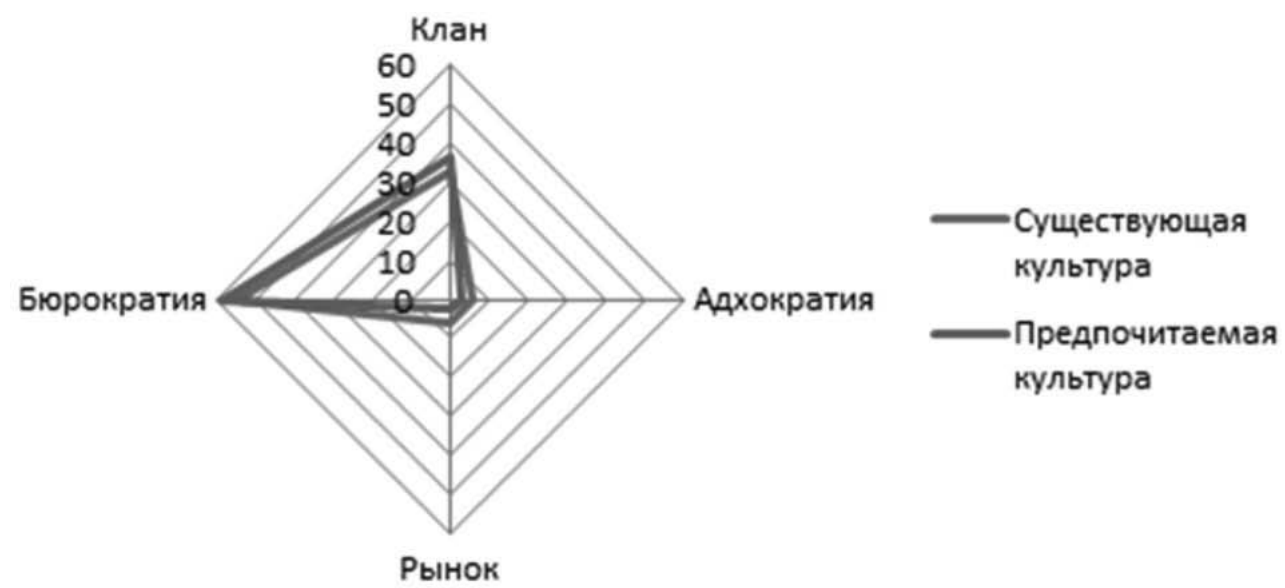

Рис. 2. Выраженность типов организационной культуры и соотношения существующей и предпочитаемой культуры сотрудников предприятия 2

тура, которая сфокусирована на получении конкретных результатов, ключевая стратегическая задача - получить желаемый итог в работе. Руководители проявляют строгость, высокие требования и не сомневаются в принятых решениях. При выраженности такого типа культуры в организации важно достигать результатов и находиться в ситуации выигрыша. Ключевая идея культуры - сохранить определенный имидж успешного предприятия, причем на это ориентированы усилия всех участников. Важно реализовывать конкретно задекларированные задачи и цели. Все это связано с растущими требованиями к конкурентоспособности организаций, их развитию, проявлению максимальной финансовой независимости. Высшее руководство и начальники подразделений это замечают и понимают раньше, чем рядовые сотрудники.

Результаты совпадения существующей и предпочитаемой культуры среди сотрудников предприятия 2, а также доминирующий тип культуры представлены на рисунке 2.

По данным рисунка 2 видно, что среди высшего руководства и начальников подразделений как существующая реально описан тип бюрократической культуры, так же, как и предпочитаемая, что может быть объяснимо тем, что руководство меньше ориентировано на развитие конкурентоспособности, изменение управленческих функций, стратегическое развитие, поэтому и сконцентрированы на выполнении традиционных обязанностей, отмеченных в инструкциях, что не требует усилий или мотивации перемен. Но количество этой группы руководителей велико, поэтому важно учитывать их мнение и видение ситуации, чтобы внесение корректив в существующую культуру было более эффективным.

Необходимо отметить, что для внедрения изменений в существующую организационную культуру необходимо учитывать не только тип культуры, его совпадение с предпочитаемым типом, должность сотрудника, но и личностные и поведенческие компоненты культуры, а именно: уровень социального доверия, базовые адаптивные реакции сотрудников и уровень организационной лояльности. По результатам анализа различных работ и исследований, представленных в теоретической части работы, именно они были выделены нами среди тех, которые оказывают влияние на возможность внесения изменений в существующую культуру.

По результатам оценки реально существующей и предпочитаемой организационной культуры респондентов в каждом предприятии удалось разделить на три условные группы (таблица 1).

Таблица 1.

Группы респондентов в соответствии с оценкой культуры

\begin{tabular}{|l|c|c|}
\multicolumn{1}{|c|}{ Тип группы } & \multicolumn{1}{|c|}{ Предприятие 1 } & Предприятие 2 \\
\hline $\begin{array}{l}\text { группа с максимальным } \\
\text { совпадением реальной и } \\
\text { предпочитаемой культуры }\end{array}$ & $13 \%$ респондентов & $83 \%$ респондентов \\
\hline $\begin{array}{l}\text { группа со средним уровнем } \\
\text { совпадения реальной и пред- } \\
\text { почитаемой культуры }\end{array}$ & $34 \%$ респондентов & $10 \%$ респондентов \\
\hline $\begin{array}{l}\text { группа с низким уровнем } \\
\text { совпадения реальной и пред- } \\
\text { почитаемой культуры }\end{array}$ & $53 \%$ респондентов & $7 \%$ респондентов \\
\hline
\end{tabular}

Можно сделать выводы, что среди сотрудников предприятия 1 большая часть с низким уровнем совпадения существующей и предпочитаемой культуры, что говорит о том, что отдельные компоненты, нормы, правила не разделяются, практически не поддерживаются даже на формальном уровне, а не искренне, «по внутренним убеждениям». Среди сотрудников предприятия 2 большая часть с высоким уровнем совпадения существующей и предпочитаемой культуры, что говорит о том, что отдельные компоненты, нормы, правила разделяются, 
поддерживаются на формальном и личностном уровнях, искренне, «по внутренним убеждениям».

В зависимости от уровня совпадения существующей и предпочитаемой культуры в организации, представлены результаты оценки личностных особенностей и особенностей поведения сотрудников, которые взаимосвязаны с возможностями внедрения изменений в существующую или новой культуры, а именно: уровня доверия, организационной лояльности.

Результаты оценки уровня социального доверия по методике «Шкала межличностного доверия» Дж. Б. Роттера представлены в таблице 2.

Таблица 2.

Уровень социального доверия* в группах респондентов с разным уровнем представления об организационной культуре

\begin{tabular}{|c|c|c|}
\hline & Предприятие 1 & Предприятие 2 \\
\hline $\begin{array}{l}\text { Низкий уровень } \\
\text { доверия }\end{array}$ & 64\% (75,4 - ср.балл) & $10 \%$ (26,7 - ср.балл) \\
\hline $\begin{array}{l}\text { Средний уровень } \\
\text { доверия }\end{array}$ & $20 \%$ (98,3 - ср.балл) & $12 \%$ (45,2 - ср.балл) \\
\hline $\begin{array}{l}\text { Высокий уровень } \\
\text { доверия }\end{array}$ & 16\% (70,4 - ср.балл) & $78 \%$ (34,5 - ср.балл) \\
\hline
\end{tabular}

* 25-67 - низкий уровень доверия; 68-108 - средний уровень доверия; 109-125 - высокий уровень доверия

По данным таблицы 2, сотрудников предприятия 2 можно описать как группу имеющую высокий уровень доверия. Им будущее кажется многообещающим, они доверяют разным категориям людей, которые их окружают, в общем, считают, что большинство людей сделают то, что говорят. Они ожидают, что окружающие будут вести себя нормально и честно, проявляя готовность к взаимопомощи в соответствии с общепринятыми нормами, правилами, нравственными ценностями и этикой поведения. Высокий уровень доверия основан на ощущении, что партнер по взаимодействию делает все на основе этичных убеждений и высокой моральности действий, также он проявляет доброту, открытость в решении профессиональных и общественных целей и задач.

Сотрудников предприятия 1 можно охарактеризовать как тех, кому будущее не кажется многообещающим, они не доверяют людям, которые их окружают, считают, что большинство людей не делают то, что говорят и обещают. Они не ожидают, что люди будут вести себя нормально и честно, проявлять готовность к взаимопомощи в соответствии с общепринятыми нормами, традициями, обычаями, соблюдать общие этические ценности. Низкий уровень доверия основан на ощущении, что партнер по взаимодействию делает все не с помощью этичных убеждений и высокой моральности действий, также он не проявляет доброту, открытость в решении профессиональных и общественных целей и задач. Чем больше совпадает представление о существующей и предпочитаемой организационной культуре, тем выше уровень доверия респондентов (данные проверены с помощью критерия Спирмена).

Еще одна методика, предложенная респондентам, была «Шкала организационной лояльности». Данные представлены в таблице 3.

Таблица 3.

Уровень лояльности* в группах респондентов с разным уровнем представления об организационной культуре

\begin{tabular}{|l|c|c|}
\hline Аффективная лояльность & Предприятие 1 & Предприятие 2 \\
\hline Нормативная лояльность & $12,4-$ ср.балл & $36,7-$ ср.балл \\
\hline Текущая лояльность & $13,4-$ ср.балл & 35,2 - ср.балл \\
\hline
\end{tabular}

* 7-14 - низкий уровень лояльности, 15-29 - средний уровень лояльности, 30-42 - высокий уровень лояльности

По данным таблицы 3 можно сделать вывод о том, что в группе респондентов предприятия 2 с высоким совпадением существующей и предпочитаемой культуры высокий уровень аффективной, нормативной и текущей лояльности. Что говорит о том, что у респондентов есть эмоциональная привязанность к организации, она имеет для сотрудника большое значение, он рассматривает свою принадлежность к ней как принадлежность к семье и желает в дальнейшем принадлежать к ней, воспринимают проблемы этой организации как свои собственные, испытывают теплые чувства к ней, организация много значит для них. Также респондентов этой группы связывают с организацией морально-этические убеждения, чувство обязательства по отношению к организации, не чувствуют себя вправе ее покинуть, даже если это будет выгодно для них, считают, что организация заслуживает их преданность. Продолжают работать в этой организации не только по желанию, но и по необходимости. Считают, что много вложили в организацию, поэтому не рассматривают работу в другом месте, считают, что, уйдя из этой организации, лишатся многих возможностей.

В группе сотрудников предприятия 1 с минимальным совпадением представлений о существующей и предпочитаемой культуре выражен средний уровень нормативной и низкий уровень аффективной и текущей лояльности. Это говорит, что у респондентов низкий уровень эмоциональной привязанности к организации в отдельных аспектах, она не имеет для сотрудника большого значения, он не чувствует свою принадлежность к ней. Сотрудники не воспринимают проблемы организации как свои, не испытывают к ней теплые чувства чаще, чем 
негативные. У респондентов этой группы с организацией не связаны никакие морально-этические убеждения, нет чувства обязательства по отношению к ней. Они могут и стремятся покинуть организацию, даже если это может не быть выгодным для них, не считают, что она заслуживает их преданности. Продолжают работать в этой организации по необходимости, а не по желанию. Не считают, что много вложили в организацию, поэтому всегда рассматривают работу в других местах, считая, что, если уйдут из данной организации, у них появятся определенные возможности.

Таким образом, респонденты с разным уровнем совпадений представлений о существующей и предпочитаемой культуре обладают разным уровнем лояльности и социального доверия, что оказывает влияние на эффективность внедрения новой организационной культуры.

Помимо оценки совпадения реальной и идеальной культуры, проявления доверия и лояльности, большое значение имеет оценка когнитивного конструкта «культура в моей организации», который является частью внутреннего мира личности, содержащей ценности, нормы и правила, связанные с поведением в организации и в рабочих процессах.

В результате анкетирования и описания данного конструкта в свободной форме, получились следующие результаты:

- на предприятии 2, где выявлено высокое совпадение реальной и идеальной культуры, когнитивный конструкт «культура в моей организации» содержит позитивные оценки, у сотрудников выражена высокая мотивация разделять нормы и правила организации, ценности, которые совпадают с тем, что транслирует руководство; сотрудники легко перечисляют ключевые позиции того, что «принято» и «не принято» в организации, выражают согласие с тем, что это правильно. Так же у них много визуальных образов, которые описывают культуру, в которой они находятся и работают: это цветовые, предметные ассоциации; также сотрудники легко находят метафоры для описания культуры и внутренних процессов в организации;

- на предприятии 1, где выявлено низкое совпадение реальной и идеальной культуры, когнитивный конструкт «культура в моей организации» содержит нейтральные или негативные оценки, у сотрудников выражена низкая мотивация разделять нормы и правила организации, ценности, которые транслирует руководство организации; сотрудникам сложно перечислить ключевые позиции того, что «принято» и «не принято» в организации, они не согласны с тем, что это правильно. У них мало визуальных образов, которые описы- вают культуру, в которой они находятся и работают: это в основном, просто описание символики и фирменных цветов организации; сотрудники не могут найти метафоры для описания культуры и внутренних процессов в организации.

Все это подтверждает идею о том, что визуальные формы, которые содержатся во внутреннем мире человека и связаны с конструктом «культура организации», позволяют ее принимать как собственную базовую ценность. Следовательно, визуализация как форма трансляции и переработки данных, может быть эффективным способом для развития и поддержания различных трансформаций в культуре организации.

С помощью критерия Манна-Уитни было выявлено, что представления о существующей и идеальной культуре в организации значительно отличаются, $\left(U_{\text {эмп }}=857,3\right.$, Uкр $=270$, при $\mathrm{p}<0,01)$, не смотря на то, что на предприятиях 1 и 2 придерживаются строгих правил, форм работы, там редко встречается творческий подход и конкуренция в отношениях, а также разнообразие в используемых правилах и нормах.

Идея о том, уровень доверия и лояльность сотрудников взаимосвязаны с желанием сотрудников участвовать в формировании и развитии организационной культуры, было проверено с помощью корреляционного анализа. Данные представлены в таблице 4.

Таблица 4.

Связи между доверием и лояльностью сотрудников и желанием создавать новую организационную культуру

\begin{tabular}{|l|l|}
\multicolumn{1}{c|}{ Шкала } & Корреляционный показатель \\
\hline $\begin{array}{l}\text { Социальное доверие и желание участво- } \\
\text { вать в создании культуры в организации }\end{array}$ & $\begin{array}{l}\mathrm{r}_{\text {эмп }}=0,201>\mathrm{r}_{\mathrm{kp}}=0,47 \text { при } \\
\mathrm{p} \leq 0,01\end{array}$ \\
\hline $\begin{array}{l}\text { Текущая лояльность и желание участво- } \\
\text { вать в создании культуры в организации }\end{array}$ & $\begin{array}{l}\mathrm{r}_{\text {эмп }}=0,321>\mathrm{r}_{\mathrm{kp}}=0,47 \text { при } \\
\mathrm{p} \leq 0,01\end{array}$ \\
\hline $\begin{array}{l}\text { Аффективная лояльность и желание } \\
\text { участвовать в создании культуры в } \\
\text { организации }\end{array}$ & $\begin{array}{l}\mathrm{r}_{\text {эмп }}=0,312>\mathrm{r}_{\mathrm{kp}}=0,47 \text { при } \\
\mathrm{p} \leq 0,01\end{array}$ \\
\hline $\begin{array}{l}\text { Нормативная лояльность и желание } \\
\text { участвовать в создании культуры в } \\
\text { организации }\end{array}$ & $\begin{array}{l}\mathrm{r}_{\text {эмп }}=0,129>\mathrm{r}_{\mathrm{kp}}=0,47 \text { при } \\
\mathrm{p} \leq 0,01\end{array}$ \\
\hline
\end{tabular}

По данным таблицы 4 можно увидеть значимые связи между отдельными типами лояльности, социальным доверием и желанием участвовать в создании организационной культуры. Что говорит о том, что при наличии данных компонентов есть вероятность эффективного формирования организационной культуры нового типа, поскольку они тесно связаны с функционированием персонала.

Таким образом, культура в организации постоянно 
трансформируется, что делает ее достаточно сложным конструктом для изучения, поэтому необходимо не только опрашивать сотрудников на предмет их оценки типа организационной культуры, но и анализировать ее по глубинным признакам, связанным с личностными проявлениями персонала: лояльностью, доверием, а также в целом изучать то, как они анализируют данный когнитивный конструкт. Все это необходимо для выработки алгоритмов трансформации организационной культуры максимально естественным путем без принуждения, сопротивления среди персонала.

В ходе эмпирического исследования были получены данные о типе организационной культуры. Были выявлены существующая и предпочтительная организационная культура в двух предприятиях со схожей сферой деятельности. Реальная и идеальная типы культур - совпадают на одном предприятии и почти противоположны на втором, что объясняется тем, что нет типичного стиля организации работы, ценностей и норм даже на схожих предприятиях.

По результатам оценки реальной и идеальной организационной культуры всех участников исследования удалось разделить на условные группы: группа с максимальным совпадением существующей и предпочитаемой организационной культуры (83\% сотрудников предприятия 2); группа с минимальным уровнем совпадения существующей и предпочитаемой организационной культуры (53\% сотрудников предприятия 1). Респонденты с высоким уровнем совпадений представлений о реальной и идеальной культуре обладают высоким уровнем лояльности и социального доверия, а респонденты с низким уровнем совпадений представлений о реальной и идеальной культуре, наоборот, обладают невысоким уровнем лояльности и социального доверия, что оказывает влияние на эффективность внедрения новой организационной культуры.

\section{ЛИТЕРАТУРА}

1. Вихорева М.В., Ершова К.Н. Соотношение понятий организационной и корпоративной культуры //Экономика и бизнес: теория и практика. - 10-1 (80). 2021. - C. 128-130. D0I: 10.24412/2411-0450-2021-10-1-128-131

2. Кудинова А.В., Лаво Р.С., Морозов С.А. Креативность и организационная культура в арт-бизнесе// Вестник Академии знаний. - № 45(4). - 2021. - С. 142146. DOI: $10.24412 / 2304-6139-2021-11347$

3. Лапшова, 0.А. Управление персоналом: учебник и практикум / 0.А. Лапшова [и др.]; под общ. ред. 0.А. Лапшовой. - М.: Юрайт, 2019. - 406 с

4. Раренко А.А. Роль организационной культуры в управлении персоналом российских организаций // Социальные и гуманитарные науки. Отечественная и зарубежная литература. Серия 11: Социология. - 2021. - № 1. - C. 138-157. D01: 10.31249/rsoc/2021.01.09

5. Смирнова, В.Г. Организационная культура: учебник и практикум / В. Г. Смирнова [и др.]; под ред. В.Г. Смирновой. - М.: Юрайт, 2019. - 306 с.

6. Тульчинский, Г.Л. Бренд-менеджмент. Брендинг и работа с персоналом: учебное пособие. - 2-е изд., испр. и доп. - М.: Юрайт, 2019. - 255 с.

7. Фролова А.А., Захарова Л.Н. Особенности организационной культуры в IT сфере //Journal of Economy and Business. - Vol. 10-2 (80). - 2021. - C. 127-130 DOl:10.24412/2411-0450-2021-10-2-127-130

○ Бюндюгова Татьяна Вячеславовна (tach_29@mail.ru).

Журнал «Современная наука: актуальные проблемы теории и практики» 